\title{
Association between Bone Mineral Density and Hypertension in Postmenopausal Women
}

\author{
S. M. Muraduzzaman, S. Begum, S. Ali, S. Sultana, M. Saiedullah, and F. Alam
}

\section{ABSTRACT}

Background: Low bone mineral density (BMD) is a common disorder in the elderly and found to be most prevalent in postmenopausal women which are thought to be associated with several factors including hypertension, however, results are inconsistent in different studies.

Aim of the study: This study aimed to explore the association between BMD and hypertension in postmenopausal women.

\begin{abstract}
Methods and materials: In this study, total 76 postmenopausal women were included. BMD was determined at the lumbar spine and femoral neck by dual-energy $x$-ray absorptiometry (DEXA). Anthropometric data and status of hypertension and diabetes were collected according to a prestructured questioner.
\end{abstract}

Results: Age (mean \pm SD) of the postmenopausal women was $57 \pm 9$ years. Among them, $46(60.5 \%)$ subjects were hypertensive and $30(39.5 \%)$ were normotensive. Bone mineral density $\left(\mathrm{g} / \mathrm{cm}^{2}\right)$ in normotensive women and in hypertensive women were $0.79 \pm 0.15$ vs $0.74 \pm 0.15(p=0.160)$ at lumbar spine; $0.70 \pm 0.12$ vs $0.69 \pm 0.13(p=0.271)$ at right femoral neck and $0.73 \pm 0.15$ vs $0.71 \pm 0.13(p=0.592)$, respectively. $T$-scores at lumbar spine, right and left femoral neck in normotensive and hypertensive postmenopausal women were $-2.28 \pm 1.37$ vs $-\mathbf{2 . 7 5} \pm 1.35 \quad(p=0.153)$, $-1.70 \pm 1.16$ vs $-1.95 \pm 1.07(p=0.363)$ and $-1.82 \pm 0.95$ vs $-1.93 \pm 1.01(p=0.632)$ respectively. On multiple regression analysis, BMD and T-score only at lumbar spine showed inverse association with hypertension $(\beta=-0.069$, $p=0.045 ; \beta=-0.612, p=0.050$ ) on adjusting confounding variables.

Conclusion: Hypertension is independently associated with BMD and Tscore measured from the lumbar spine but not with BMD and T-score measured from the femoral neck in postmenopausal women.

Keywords: Bone mineral density, Hypertension, Postmenopausal women, $\mathrm{T}$-score.
Submitted : July 15, 2021

Published : August 06, 2021

ISSN: 2593-8339

DOI: $10.24018 /$ ejmed.2021.3.4.980

\section{S. M. Muraduzzaman}

Dept of Biomedical Engineering \& Medical Physics, Bangladesh University of Health Sciences (BUHS), Dhaka, Bangladesh.

(e-mail: projuktimurad@ gmail.com) S. Begum

Dept of Applied Laboratory Sciences, Bangladesh University of Health Sciences (BUHS), Dhaka, Bangladesh.

(e-mail: shahnajbegum0002@gmail.com) S. Ali

Dept of Biochemistry and Cell Biology, Bangladesh University of Health Sciences (BUHS), Dhaka, Bangladesh.

(e-mail: shahajahan18591@ gmail.com)

S. Sultana

National Institute of Nuclear Medicine \& Allied Sciences, Bangladesh Atomic Energy Commission, Dhaka, Bangladesh. M. Saiedullah*

Dept of Biochemistry and Cell Biology, Bangladesh University of Health Sciences (BUHS), Dhaka, Bangladesh.

(e-mail: md.saiedullah@gmail.com)

F. Alam

Dept of Radiology and Imaging

Technology, Bangladesh University of Health Sciences (BUHS), Dhaka, Bangladesh.

(e-mail: vc@buhs.ac.bd)

*Corresponding Author

\section{INTRODUCTION}

With the increasing elderly population and change in lifestyle, hypertension and osteoporosis are becoming important non-communicable public health problems in the world [1]-[3]. In osteoporosis, loss of bone mass and deterioration of bone tissue microarchitecture led to increase bone fragility and the concomitant rise in fracture risk [4]. The incidence of hip fracture due to osteoporosis is higher in developing countries and 6.3 million of the global population is expected to be affected by the year 2050, [5]. The prevalence of osteoporosis was $9 \%, 15 \%, 26 \%$ among elderly non-Hispanic black, non-Hispanic whites, and Mexican Americans respectively [6]. In Korea, Japan, China, Taiwan, and Sri Lanka, it is between $24-40 \%$ among middle-aged women [7]-[13]. In the Bangladeshi population, the scenario is similar where $41.8 \%$ of elders (above 45 years of age) women found to have osteoporosis and in postmenopausal women, it was observed in $49.6 \%$ [14]. Bone mineral density (BMD) and Bone mineral content (BMC) are the common tests for the diagnosis of osteoporosis and prediction of fracture risk, various studies suggest that the common risk factors for osteoporosis include age, gender, smoking, coronary heart disease, diabetes, essential hypertension, decreased estrogen level etc. [15]-[17]. Menopause is a physiological condition for elderly women. With the improvement in diagnosis and treatment, life expectancy after menopause has increased in women. After menopause, 
abnormality in calcium (Ca) metabolism and reduction of BMD have found to be associated with osteoporosis [18]. Several studies showed that abnormal $\mathrm{Ca}$ metabolism is associated with hypertension, but the results are inconclusive [19]-[24]. Besides the effect on Ca metabolism, hypertension also causes secondary activation of the parathyroid gland which results in increased Ca movement from bone [25]-[28]. Hypertension affects the kidney's ability to handle $\mathrm{Ca}$ and age-related excessive reduction in BMD. It has also been reported that increased angiotensin II level increases bone resorption and bone demineralization leading to negative effects in hypertensive patients [29]-[31]. Several studies show a negative correlation between hypertension and BMD [22], [32]. A study done on white elderly women found that high blood pressure (BP) is associated with increased bone loss in the femoral neck [31]. Yang et al. [32] have also reported similar association. In another study, done on postmenopausal women in North India found a negative association between hypertension and BMD [33]. The negative association between hypertension and BMD has also been supported by a meta-analysis [34]. In opposite, there are studies also that have found no relation between hypertension and BMD [35], [36]. However, based on the National Health and Nutrition Examination Survey (NHANES) data, Mussolino et al. reported no significant association between BMD and hypertension in African American Population [37]. No significant differences of BMD in different body parts were found between hypertensive and normotensive groups in a study done on Turkish post-menopausal women [38]. Since there are controversial findings in different studies, the need for new studies on the association of hypertension and BMD arises. Besides, there was no study found on Bangladeshi post-menopausal women, which focuses on the association between hypertension and BMD. So our study aimed to find whether there is an association between hypertension and BMD in postmenopausal women of Bangladesh.

\section{MATERIAL AND METHODS}

\section{A. Study Design and Sample}

This cross-sectional study was conducted in the Dept. of Applied Laboratory Sciences, Bangladesh University of Health Sciences (BUHS), Dhaka, Bangladesh, and National Institute of Nuclear Medicine \& Allied Sciences, Bangladesh Atomic Energy Commission. Seventy-six (76) postMenopausal women who came for screening for osteopenia or osteoporosis by dual-energy X-ray absorptiometry (DEXA) from June 2018 to July 2019, were included in this study. Among them 30 subjects were normotensive and 46 were hypertensive. Subjects with comorbid diseases (infection, stroke, myocardial infarction, major surgery, coronary heart disease, thyroid diseases, severe liver or renal disease, neoplasm, hematological disorders, taking anticoagulants etc.) were excluded from the study.

\section{B. Measurements of Risk Variables}

Subjects with blood pressure $\geq 140 \mathrm{mmHg}$ and/or $\geq 90 \mathrm{mmHg}$, and/or using antihypertensive medication were considered hypertensive. Body mass index (BMI) of the subjects was calculated in $\mathrm{kg} / \mathrm{m}^{2}$ using the standard formula:

$$
\text { BMI }=\text { Weight }(\mathrm{kg}) /[\text { Height }(\mathrm{m})]^{2}
$$

\section{Bone Mineral Density Scans}

Bone mineral density $\left(\mathrm{g} / \mathrm{cm}^{2}\right)$ was measured for the lumbar spine (L2 to L4) and proximal femur using a GE Lunar DPXNT PRO (Lunar Corp, Adison, WI, USA) by DXA scanning. Bone mineral density was determined according to standard protocols and expressed in $\mathrm{g} / \mathrm{cm}^{2}$ and as peak bone mass percentage in normal subjects (T-score) depending on the software used in the device.

\section{Statistical Analysis}

All continuous variables were tested for skewness. The distribution of all variables was normal. The continuous parameters were presented as mean \pm standard deviation. Comparisons of demographic, clinical and laboratory characteristics of the patients were performed using an independent sample t-test. Multivariate logistic regression analysis was used to assess the independent association of BMD with hypertension. Statistical analyses were carried out using MedCalc version 11.4 for Windows and a p-value $<0.05$ was considered as significant.

\section{RESULTS}

\section{A. Characteristics of the Study Subjects}

Total 76 postmenopausal women were included in this study. The age range was 35 to 85 years. Characteristics of the study subjects were presented in Table I. Among the subjects 46(60.5\%) were hypertensive and 30(39.5\%) were normotensive; $25(32.9 \%$ ) were diabetic and 51(67.1\%) were nondiabetic. The mean $\pm \mathrm{SD}$ of BMI was $26.1 \pm 4.7 \mathrm{Kg} / \mathrm{m}^{2}$ among them 32 subjects were overweight (BMI: 25$30 \mathrm{~kg} / \mathrm{m}^{2}$ ) and 12 subjects were obese $\left(\mathrm{BMI}>30 \mathrm{~kg} / \mathrm{m}^{2}\right)$. Age distributions of the subjects are presented in Fig 1. Most of the study subjects $(47.4 \%)$ were within the age group 51-64 years, followed by $38-51(27.6 \%)$ and $64-77$ (23.7\%) years; the age distribution followed a normal distribution $(\mathrm{p}=0.249)$

\begin{tabular}{cc} 
TABLE I: CHARACTERISTICS OF THE STUDY SUBJECTS \\
\hline Variable & Mean \pm SD/\% \\
\hline Age (years) & $57 \pm 9$ \\
BMI (kg/m ${ }^{2}$ ) & $26.1 \pm 4.7$ \\
Hypertension (yes) & $60.5 \%$ \\
Systolic blood pressure (mmHg) & $123 \pm 17$ \\
Diastolic blood pressure (mmHg) & $77 \pm 10$ \\
Diabetes (yes) & $32.9 \%$ \\
\hline
\end{tabular}

Results were expressed as mean $\pm \mathrm{SD} / \%$.

BMI, Body mass index.

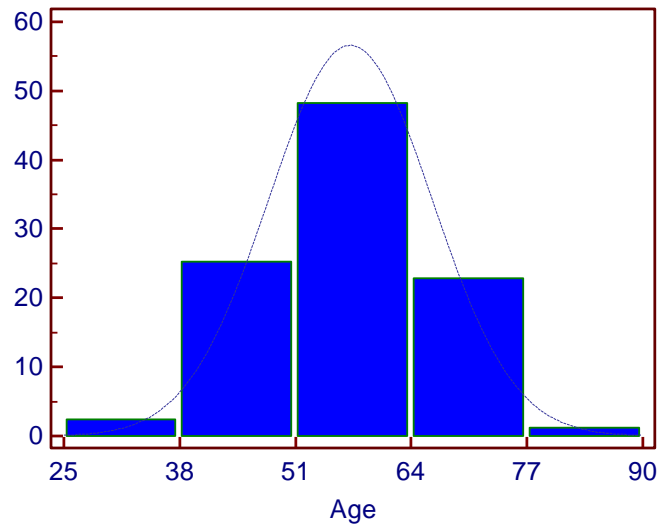

Fig. 1. Age distribution of the study subjects. 


\section{B. Bone Mineral Density in the Study Subjects}

Bone mineral density (BMD) in Lumbar spine and femoral neck is presented in Table II. BMD was similar in right and left femoral neck and density was higher in lumbar spine than femoral spine.

TABLE II: BMD IN LUMBAR SPINE AND FEMORAL NECK

\begin{tabular}{ccc}
\hline Area & BMD $\left(\mathrm{g} / \mathrm{cm}^{2}\right)$ & T-score \\
\hline Lumbar spine & $0.76 \pm 0.15$ & $-2.56 \pm 1.37$ \\
Right femoral neck & $0.71 \pm 0.14$ & $-1.85 \pm 1.11$ \\
Left femoral neck & $0.71 \pm 0.13$ & $-1.88 \pm 0.99$ \\
\hline
\end{tabular}

C. Comparison of BMD between Normotensive and Hypertensive Postmenopausal Women

Bone mineral density $\left(\mathrm{g} / \mathrm{cm}^{2}\right)$ at the lumbar spine was higher in normotensive postmenopausal women $(0.79 \pm 0.15)$ and hypertensive postmenopausal women $(0.74 \pm 0.15)$ but it was not statistically significant $(\mathrm{p}=0.160)$. Similarly, hypertensive postmenopausal women had lower BMD $\left(\mathrm{g} / \mathrm{cm}^{2}\right)$ at right and left femoral neck $(0.69 \pm 0.13$ and $0.70 \pm 0.12)$ compared to normotensive postmenopausal women $(0.73 \pm 0.15$ and $0.71 \pm 0.13)$ but failed to reach statistical significance (both, $\mathrm{p}>0.05$ ) (Fig. 2). T-score at the lumbar spine and femoral neck showed no significant difference between normotensive and hypertensive subjects $[-2.28 \pm 1.37$ vs $-2.75 \pm 1.35 ;-1.70 \pm 1.16$ vs $-1.95 \pm 1.07$ and $-1.82 \pm 0.95$ vs $-1.93 \pm 1.01$, respectively (Fig. 3)].
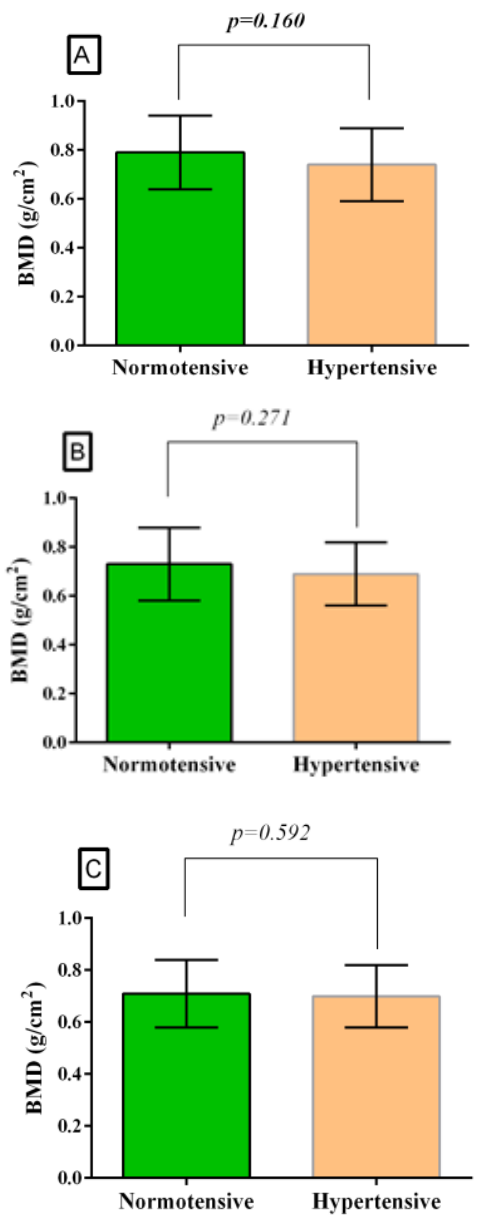

Fig. 2. Comparison of BMD between normotensive and hypertensive postmenopausal women at lumbar spine (A), right femoral neck (B) and left femoral neck $(\mathrm{C})$.
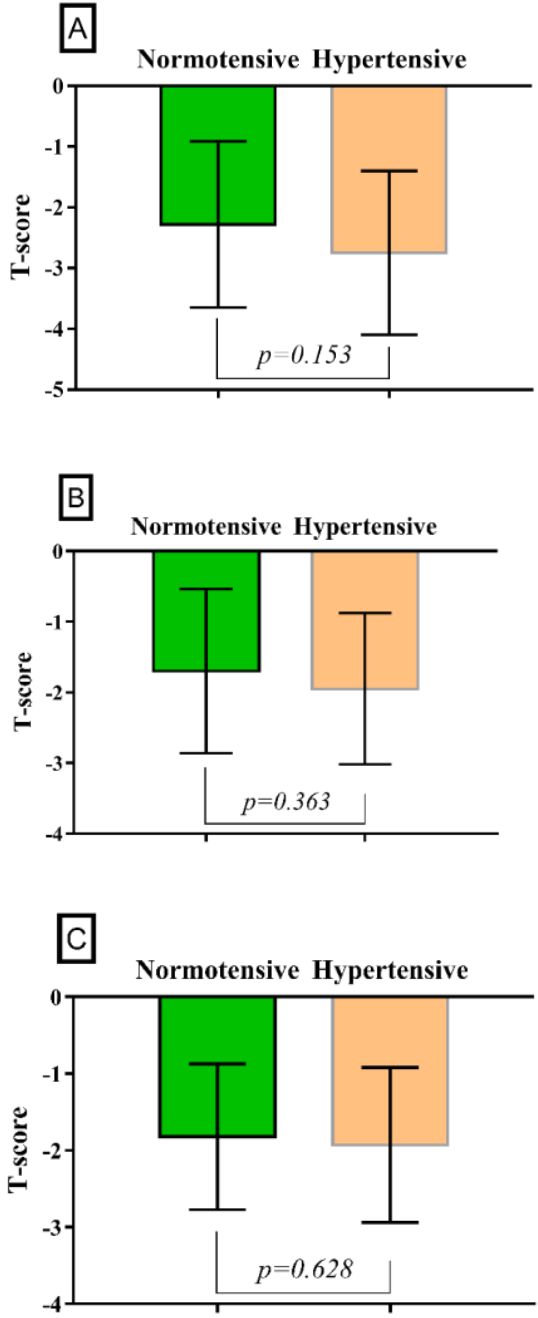

Fig. 3. Comparison of T-score between normotensive and hypertensive postmenopausal women at lumbar spine (A), right femoral neck (B) and left femoral neck (C).

\section{Multiple Regression Analysis}

Unadjusted coefficient $(\beta)$ in multiple regression analysis considering BMD at the lumbar spine, right femoral neck or left femoral neck as dependent variable and hypertension, diabetes, age, and BMI as independent variables presented in Table III. In all cases, BMI showed a positive association with BMD. However, hypertension showed an inverse association with BMD and reached statistical significance at the lumbar spine (Table III).

TABLE III: COEFFICIENT OF BMD WITH HYPERTENSION IN MULTIPLE REGRESSION ANALYSIS

\begin{tabular}{|c|c|c|c|c|c|c|}
\hline & \multicolumn{2}{|c|}{ Lumbar spine } & \multicolumn{2}{|c|}{ Right femoral neck } & \multicolumn{2}{|c|}{ Left femoral neck } \\
\hline $\begin{array}{l}\text { BMD } \\
\left(\mathrm{g} / \mathrm{cm}^{2}\right)\end{array}$ & $\beta$ & $\begin{array}{c}\mathrm{p}- \\
\text { value }\end{array}$ & $\beta$ & $\begin{array}{c}\mathrm{p}- \\
\text { value }\end{array}$ & $\beta$ & p-value \\
\hline Age & -0.002 & 0.917 & -0.004 & 0.035 & -0.003 & 0.075 \\
\hline BMI & 0.014 & 0.002 & 0.007 & 0.029 & 0.007 & 0.023 \\
\hline HTN & -0.069 & 0.045 & -0.040 & 0.209 & -0.019 & 0.503 \\
\hline DM & -0.004 & 0.910 & 0.004 & 0.889 & 0.001 & 0.997 \\
\hline $\begin{array}{c}\text { T- } \\
\text { score }\end{array}$ & & & & & & \\
\hline Age & -0.004 & 0.802 & -0.029 & 0.034 & -0.023 & 0.059 \\
\hline BMI & 0.121 & 0.004 & 0.057 & 0.037 & 0.056 & 0.023 \\
\hline HTN & -0.612 & 0.050 & -0.257 & 0.315 & -0.136 & 0.552 \\
\hline DM & -0.070 & 0.824 & 0.001 & 0.997 & -0.007 & 0.977 \\
\hline
\end{tabular}

BMI, body mass index; HTN, hypertension and DM, diabetes mellitus. 


\section{DisCUSSION}

In this study, analysis of BMD by DEXA method showed similar results for BMD and T score at lumbar femur in both postmenopausal normotensive and hypertensive women. Hypertension was found to be independently associated with BMD and T-score measured from the lumbar spine but not with BMD and T-score measured from the femoral neck on multiple regression analysis.

Metabolic changes occur more prominently in Trabecular bone (Lumber spine) than Cortical bone (Femoral Neck) [39]. The association between hypertension and osteopenia is shown to be different for different sites of bone [40-42] and found to be inconsistent in different races [22], [23], [31], [40]-[46]. Tsuda et al. found an inverse relationship between lumbar spine BMD and SBP in Japanese women [43]. In another study, Gotoh et al. found an association between abnormal Ca metabolism and hypertension [44]. In a study done on post-menopausal women, Afghani et al. found a negative association between hypertension and bone mineral content (BMC). Here SBP was independently associated with BMC but the association with BMD was not done [45]. Cappuccio et al. found an inverse relationship between femoral neck BMD and blood pressure in a study done on white postmenopausal elderly women [22]. However, the difference to our study, their study was performed only on the femoral neck they could not establish the association at different sites. Lidfeldt et al. found a positive association between BMD and SBP without adjusting confounding variables [23]. Yang et al. also found a lower BMD at the femoral neck in hypertensive women compared to normotensive women $\left(0.79\right.$ versus $\left.0.82 \mathrm{~g} / \mathrm{cm}^{2}, \mathrm{P}=0.02\right)$ [32]. In North Indian post-menopausal women, a similar finding was reported [33]. The inverse relationship between hypertension and BMD was also evident from the Metaanalysis [34].

Some studies conclude no significant relationship between hypertension and BMD [37], [47]. In these studies, BMD was measured only from the femoral neck, and they could not find any association between hypertension and BMD. However, as it is established that BMD differs with different sites of bone, we performed our study on both the Lumber spine and femoral neck and found that hypertension is independently associated with BMD measured only from the Lumbar spine. Primary Hypertension has an association with $\mathrm{Ca}$ metabolism, which causes loss of $\mathrm{Ca}$ and secondary activation of the parathyroid gland causing increased removal of Ca from bone [19]-[23].

These differences in findings of different studies may be due to differences in patient selections (such as age, ethnicity, sample size, the inclusion of patients with comorbidities, extent and etiology of osteoporosis or hypertension) and diagnostic methods or criteria. In our study, we only included postmenopausal women, therefore; the findings are not generalizable to men or younger women. Moreover, the cross-sectional study design of the study made it impossible to find any cause-effect relationship between hypertension and BMD in postmenopausal women. So, a prospectively designed study with a bigger sample size, which incorporates the measurement of biochemical indices of bone mineral metabolism, is required to be done to grasp the relationship between hypertension and BMD.
In conclusion, the current study is the first to seek out the association between hypertension and bone mineral density in postmenopausal Bangladeshi women. The presence of hypertension was found to be an independent predictor of low bone density.

\section{CONCLUSION}

BMD and T-scores at lumbar and femur are similar in postmenopausal normotensive and postmenopausal hypertensive women. Hypertension is independently associated with BMD and T-score measured from the lumbar spine but not with BMD and T-score measured from the femoral neck in postmenopausal women.

\section{ACKNOWLEDGMENT}

Funding: This study was supported by The Ministry of Science and Technology (MoST), Bangladesh.

\section{REFERENCES}

[1] A. Svedbom, E. Hernlund, M. Ivergård, J. Compston, C. Cooper, J. Stenmark, E.V. Mccloskey, B. Jönsson, and J.A. Kanis, "Osteoporosis in the European Union: a compendium of country-specific reports" Arch Osteoporos, vol. 8, pp. 137, 2013.

[2] T. Willson, S.D. Nelson, J. Newbold, R.E. Nelson, and J. Lafleur, "The clinical epidemiology of male osteoporosis: a review of the recent literature," Clin Epidemiol, vol. 2015, pp. 65-76, 2015.

[3] M. Peterlik, E. Kállay, and H.S. Cross, "Calcium nutrition and extracellular calcium sensing: relevance for the pathogenesis of osteoporosis, cancer and cardiovascular diseases," Nutrients, vol. 5, pp. 302-327, 2013.

[4] R.S. Filip, and J. Zagorski, "Bone mineral density and osteoporosis in rural and urban women. Epidemiological study of the Lublin region (Eastern Poland)," Ann Agric Environ Med, vol. 8, pp. 221-226, 2001.

[5] L. Melton, "Hip fractures: a worldwide problem today and tomorrow," Bone, vol. 14, pp. 1-8, 1993.

[6] A.C. Looker, L.G. Borrud, B. Dawson-Hughes, J.A. Shepherd, and N.C. Wright, "Osteoporosis or low bone mass at the femur neck or lumbar spine in older adults: United States, 2005-2008," NCHS Data Brief, vol. 93, pp. 1-8, 2012.

[7] X.P. Wu, E.Y. Liao, G. Huang, R.C. Dai, and H. Zhang, “A comparison study of the reference curves of bone mineral density at different skeletal sites in native Chinese, Japanese, and American Caucasian women," Calcif Tissue Int, vol. 73, pp. 122-132, 2003.

[8] L.H. Cui, J.S. Choi, M.H. Shin, S.S. Kweon, K.S. Park, Y.H. Lee, H.S. Nam, S.K Jeong, and J.S. Im, "Prevalence of osteoporosis and reference data for lumbar spine and hip bone mineral density in a Korean population," J Bone Miner Metab, vol. 26, pp. 609-617, 2008.

[9] X.P. Wu, E.Y. Liao, H. Zhang, R.C. Dai, P.F. Shan, X.Z. Cao, S.P. Liu, and Y. Jiang, "Determination of age-specific bone mineral density and comparison of diagnosis and prevalence of primary osteoporosis in Chinese women based on both Chinese and World Health Organization criteria," J Bone Miner Metab, vol. 22, pp. 382-391, 2004.

[10] M. Iki, S. Kagamimori, Y. Kagawa, T. Matsuzaki, H. Yoneshima, and F. Marumo, "Bone mineral density of the spine, hip and distal forearm in representative samples of the Japanese female population: Japanese Population-Based Osteoporosis (JPOS) Study," Osteoporos Int, vol. 12, pp. 529-537, 2001.

[11] T. S. Yang, Y.R. Chen, Y.J. Chen, C.Y. Chang, and H.T. Ng, "Osteoporosis: Prevalence in Taiwanese women," Osteoporos Int, vol. 15, pp. 345-347, 2004.

[12] C. S. Shin, H. J. Choi, M. J. Kim, J. T. Kim, S. H. Yu, B. K. Koo, H. Y. Cho, S. W. Cho, S. W. Kim, Y. J. Park, H. C. Jang, S. Y. Kim, and N. H. Cho, "Prevalence and risk factors of osteoporosis in Korea: A community-based cohort study with lumbar spine and hip bone mineral density," Bone, vol. 47, pp. 378-387, 2010.

[13] A. L. Karunanayake, M. J. Pinidiyapathirage, and A. R. Wickremasinghe, "Prevalence and predictors of osteoporosis in an urban Sri Lankan population,” Int J Rheum Dis, vol. 13, pp. 385-390, 2010 . 
[14] A. Ahmed, W. Haque, K. Uddin, F. Abrar, F. Afroz, H. Huque, and S. Afroze, "Vitamin D and bone mineral density status among postmenopausal Bangladeshi women," IMC Journal of Medical Science, vol. 12, pp. 44-49, 2019.

[15] F. Pouresmaeili, B. Kamalidehghan, M. Kamarehei, and Y. M. Goh, "A comprehensive overview on osteoporosis and its risk factors," Ther Clin Risk Manag, vol. 14, pp. 2029-2049, 2018.

[16] P. C. Hsiao, T. J. Chen, C. Y. Li, C. M. Chu, T. P. Su, S. H. Wang, H. H. Pan, and K. Y. Wang, "Risk factors and incidence of repeat osteoporotic fractures among the elderly in Taiwan: a population-based cohort study," Medicine (Baltimore), vol. 94, pp. e532, 2015.

[17] F. Afshinnia, S. Chacko, and T. Zahedi, "Association of lower serum cholesterol levels with higher risk of osteoporosis in type 2 diabetes," Endocr Pract, vol. 13, pp. 620-628, 2007.

[18] P. A. Hoover, C. E. Webber, L. F. Beaumont, and J. M. Blake, "Postmenopausal bone mineral density: relationship to calcium intake, calcium absorption, residual estrogen, body composition, and physical activity," Can J Physiol Pharmacol, vol. 74, pp. 911-917, 1996.

[19] D. A. McCarron, P. A. Pingree, R. J. Rubin, S. M. Gaucher, M. Molitch, and S. Krutsik S, "Enhanced parathyroid function in essential hypertension: a homeostatic response to a urinary calcium leak. Hypertension, vol. 2, pp. 162-168, 1980.

[20] Y. Izawa, K. Sagara, T. Kadata, and T. Makita, "Bone disorders in spontaneously hypertensive rats (Abstract)," Calcif Tissue Int, vol. 37, pp. 605-6077, 1985.

[21] M. Cirillo, F. Galletti, P. Strazzullo, L. Torielli, and M. C. Melloni, "On the pathogenetic mechanism of hypercalciuria in genetically hypertensive rats of the Milan strain," Am J Hypertens, vol. 2, pp. 741$746,1989$.

[22] F. P. Cappuccio, E. Meilahn, J. M. Zmuda, and J. A. Cauley JA, "High blood pressure and bone-mineral loss in elderly women: a prospective study," Lancet, vol. 354, pp. 971-975, 1999.

[23] J. Lidfeldt, L. Holmdahl, G. Samsioe, C. Nerbrand, P. Nyberg, B. Scherstén, C. D. Agardh, "The influence of hormonal status and features of the metabolic syndrome on bone density: a populationbased study of Swedish women aged 50 to 59 years. The Women's Health in the Lund Area Study," Metabolism, vol. 51, pp. 267-270, 2002.

[24] D. McGrowder, A. Williams, L. Gordon, T. Crawford, R. AlexanderLindo, R. Irving, M. Hamilton, and Y. Fraser, "Hypocalciuria in preeclampsia and gestational hypertension due to decreased fractional excretion of calcium," Arch Med Sci, vol. 5, pp. 80-85, 2009.

[25] E. W. Young, C. D. Morris, and D. A. McCarron, "Urinary calcium excretion in essential hypertension," J Lab Clin Med, vol. 120, pp. 624 632, 1992.

[26] D. E. Grobbee, W. H. L. Hackeng, J. C. Birkenhager, and A. Hofman, "Raised plasma intact parathyroid hormone concentrations in young people with mildly raised blood pressure," Br Med J (Clin Res Ed), vol. 296, pp. 814-816, 1988.

[27] A. S. Brickman, M. D. Nyby, K. von Hungen, P. Eggena, and M. L. Tuck, "Calcitropic hormones, platelet calcium and blood pressure in essential hypertension,” Hypertension, vol. 16, pp. 515-522, 1990

[28] M. Gadallah, S. G. Massry, R. Bigazzi, R. L. Horst, P. Eggena, V. M. Campese, "Intestinal absorption of calcium and calcium metabolism in patients with essential hypertension and normal renal function," Am J Hypertens, vol. 4, pp. 404-409, 1991.

[29] R. Hatton, M. Stimpell, and T. J. Chambers, "Angiotensin II isgenerated from angiotensin I by bone cells and stimulatesosteoclastic bone resorption in vitro," J Endocrinol, vol. 152, pp. 5-10, 1997.

[30] Y. Hiruma, A. Inoue, S. Hirose, and H. Hagiwara, "Angiotensin II stimulates the proliferation of osteoblast-rich populations of cells from rat calvariae,” Biochem Byophys Res Commun, vol. 230, pp. 176-178, 1997.

[31] J. L. Perez-Castrillon, I. Justo, and J. Silva, "Bone mass and bone modelling markers in hypertensive postmenopausal women," J Hum Hypertens, vol. 17, pp. 107-110, 2003.

[32] S. Yang, N. D. Nguyen, J. R. Center, J. A. Eisman, and T. V. Nguyen, "Association between hypertension and fragility fracture: a longitudinal study," Osteoporos Int, vol. 25, pp. 97-103, 2014.

[33] M. Kaur, "Prevalence and association of hypertension and bone mineral density among postmenopausal women of North India," Health Sci Res, vol. 2(6), pp. 50-54, 2015.

[34] Z. Ye, H. Lu, and P. Liu P, "Association between essential hypertension and bone mineral density: a systematic review and metaanalysis," Oncotarget, vol. 8, pp. 68916, 2017.

[35] F. Javed, S. A. Khan, E. W. Ayers, E. F. Aziz, M. S. Akram, G. N. Nadkarni, M. S. Sabharwal, Z. Ahmad, A. M. Benjo, and E. Herzog, "Association of hypertension and bone mineral density in an elderly African American female population," J Natl Med Assoc, vol. 104, pp. 172-178, 2012.

[36] M. Zhang, L. Yagang, L. Ying, P. Xuena, L. Binbin, G. Zhong, and L. Qiang, "Study on the influencing factors for bone mineral density among 24831 people in Changchun (Abstract)," Chin J Osteoporos, vol. 2, pp. 125-127, 2010.

[37] M. E. Mussolino, J. H. Madans, and R. F. Gillum, "Bone mineral density and hypertension prevalence in postmenopausal women: result from Third National Health and Nutrition Examination Survey," Ann Epidemiol,vol. 16, pp. 395-399, 2006.

[38] S. Yazici, M. Yazici, U. Korkmaz, M. E. Erkan, A. E. Baki, I. Erden, H. Ozhan, and S. Ataoğlu, "Relationship between blood pressure levels and bone mineral density in postmenopausal Turkish women," Arch Med Sci, vol. 7, pp. 264-70, 2011.

[39] K. Tsurusaki, M. Ito, and K. Hayashi, "Differential effects of menopaus and metabolic disease on trabecular and cortical bone assessed by peripheral quantitative computed tomography (pQCT)," Br J Radiol, vol. 73, pp. 14-22, 2000.

[40] J. A. Metz, C. D. Morris, L. A. Roberts, M. R. McClung, and D. A. McCarron, "Blood pressure and calcium intake are related to bone density in adult males," Br J Nutr, vol. 81, pp. 383-8, 1999.

[41] E. A. Jankowska, C. Susanne, E. Roguckay, and M. Medras, "The inverse relationship between bone status and blood pressure among Polish men," Ann Hum Biol, vol. 29, pp. 63-73, 2002.

[42] B. Larijani, M. R. Bekheirnia, A. Soltani, A. Khalili-Far, H. Adibi, and R. B. Jalili, "The bone mineral density is related to blood pressure in men," Am J Hum Biol, vol. 16, pp. 168-71, 2004.

[43] K. Tsuda, I. Nishio, and Y. Masuyama, "Bone mineral density in women with essential hypertension,” Am J Hypertens, vol. 14, pp. 7047, 2001.

[44] M. Gotoh, K. Mizuno, Y. Ono, and M. Takahashi, "Fluvastatin increases bone mineral density in postmenopausal women," Fukushima J Med Sci, vol. 57, pp. 19-27, 2011.

[45] A. Afghani, and C. A. Johnson, "Resting blood pressure and bone mineral content are inversly related in overweight and obese Hispanic women," Am J Hypertens, vol. 19, pp. 286-92, 2006.

[46] J. R. Buchanan, C. Myers, T. Lloyd, and R. B. Greer III, "Early vertebral trabecular bone loss in normal premenopausal women," J Bone Miner Res, vol. 3, pp. 583-587, 1988.

[47] M. E. Mussolino, J. H. Madans, and R. F. Gillum, "Bone mineral density, blood pressure, and stroke in elderly women," Stroke, vol. 34, pp. e210-11, 2003. 